\title{
Comparison Between Monochorionic and Dichorionic Placentas With Special Attention to Vascular Anastomoses and Placental Share
}

\author{
Depeng Zhao, ${ }^{1,2}$ Michal Lipa, ${ }^{3}$ Miroslaw Wielgos, ${ }^{3}$ Danielle Cohen, ${ }^{4}$ Johanna M Middeldorp, ${ }^{5}$ \\ Dick Oepkes, ${ }^{5}$ and Enrico Lopriore ${ }^{2}$ \\ ${ }^{1}$ Fetal Medicine Unit \& Prenatal Diagnosis Center, Department of Obstetrics, Shanghai First Maternity and Infant Hospital, \\ Tongji University School of Medicine, Shanghai, China \\ ${ }^{2}$ Division of Neonatology, Department of Pediatrics, Leiden University Medical Center, Leiden, the Netherlands \\ ${ }^{3} 1$ st Department of Obstetrics and Gynecology, Medical University of Warsaw, Warsaw, Poland \\ ${ }^{4}$ Department of Pathology, Leiden University Medical Center, Leiden, the Netherlands \\ ${ }^{5}$ Division of Fetal Medicine, Department of Obstetrics, Leiden University Medical Center, Leiden, the Netherlands
}

\begin{abstract}
Placental vascular anastomoses in twins lead to a shared circulation and may subsequently enable the development of severe complications such as twin-twin transfusion syndrome (TTTS) and twin anemiapolycythemia sequence (TAPS). The presence of vascular anastomoses has frequently and systematically been studied in monochorionic (MC) placentas, but only rarely in dichorionic (DC) placentas. The aim of this study was to compare the prevalence of vascular anastomoses and evaluate the sharing discordance in $\mathrm{MC}$ and DC placentas. All consecutive placentas of $\mathrm{MC}$ and DC twins delivered at the Leiden University Medical Center (the Netherlands) and Medical University of Warsaw (Poland) from 2012 to 2015 were routinely injected with colored dye and included in the study. We excluded twin pregnancies treated with fetoscopic laser surgery. A total of 258 placentas were analyzed in this study, including $134 \mathrm{MC}$ placentas and 124 DC placentas. Vascular anastomoses were present in $99 \%(133 / 134)$ of MC placentas and $0 \%$ of DC placentas $(p<.01)$. Placental share discordance between MC twins was significantly larger compared to DC twins, 19.8 (interquartile range [IQR] 8.1-33.3) and 10.8 (IOR 6.2-19.0), respectively ( $p<01$ ). Vascular anastomoses associated complications occurred in 16\% (22/134) MC twins. Our findings show that vascular anastomoses are almost ubiquitous in MC placentas, but non-existent in DC placentas. In addition, unequal placental sharing appears to be more common in $\mathrm{MC}$ than in DC placentas.
\end{abstract}

Keywords: monochorionic placenta, dichorionic placenta, vascular anastomoses, unequal placental share

MC twins are at substantially increased risk of adverse outcome compared to DC twins (Sebire et al., 1997). This excess of adversity in MC twins is mainly attributed to the complications resulting from connected circulation (Lewi et al., 2008). The vascular anastomoses are the anatomical basis for connected circulation within twin pairs. Three types of vascular anastomoses are reported in injection studies of MC placentas, namely arterio-arterial (AA) anastomoses, veno-venous (VV) anastomoses, and arterio-venous (AV) anastomoses. The unidirectional blood flow in AV anastomoses enables volume disequilibrium, resulting in severe complications such as TTTS and TAPS (Lopriore et al., 2007). The association between TTTS/TAPS and vascular anastomoses in MC twins has been extensively illustrated in placental injection studies (De Paepe et al., 2010; de Villiers et al., 2013; 2015; Denbow et al., 2000; Zhao et al., 2014). In contrast, little is known of the vascular anastomoses in DC placentas due to lack of placental injection for DC placentas. In addition, placental share discordance is quite common in MC twins, leading to discordant fetal growth, even selective intrauterine growth restriction (sIUGR; Fick et al., 2006; Lewi et al., 2007). Again, since placental injection is not routine practice for the examination of DC placenta, the placental share discordance in DC twins remains to be elucidated. The aim of this study was to compare the

RECEIVED 27 January 2016; ACCEPTED 1 March 2016. First published online 12 April 2016.

ADDRESS FOR CORRESPONDENCE: Enrico Lopriore, Department of Pediatrics, Leiden University Medical Center, J6-S, Albinusdreef 2, 2333 ZA, Leiden, the Netherlands. E-mail: e.lopriore@lumc.nl 
TABLE 1

Baseline Characteristics

\begin{tabular}{lllr}
\hline & Monochorionic twins $(n=134)$ & Dichorionic twins $(n=124)$ & $p$ value \\
\hline Gestational age at birth - wks & $33.0 \pm 4.1$ & $34.5 \pm 3.6$ & $<.01$ \\
Birth weight - gr & $1833 \pm 762$ & $2202 \pm 725$ & $<.01$ \\
Birth weight discordance - \% & $12.2(6.8-25.0)$ & $9.8(5.4-18.1)$ & .02 \\
Birth weight discordance $\geq 25 \%-n(\%)$ & $31(23)$ & $12(10)$ & $<.01$ \\
Cesarean section $-n(\%)$ & $88(66)$ & $44(35)$ & $<.01$ \\
Inter-twin Hb difference at birth - g/dL & $2.1(0.6-4.2)$ & $1.5(0.3-3.4)$ & .03 \\
\hline
\end{tabular}

Note: Data was displayed as mean $\pm S D$, median (IQR) or $n(\%)$.

placental characteristics between a large cohort of $\mathrm{MC}$ and DC placentas using colored dye injection.

\section{Materials and Methods}

All placentas of twin pregnancies consecutively delivered at Leiden University Medical Center (the Netherlands) and Medical University of Warsaw (Poland) from September 2012 to December 2015 were eligible for this study. MC placentas treated with fetoscopic laser surgery were excluded. We also excluded twin placentas with single or double fetal demise, incomplete injection due to maceration, fixation in formalin, and severe damage. Chorionicity was evaluated during the 11-14 weeks' sonographic examination and was confirmed post-natally by macroscopic or microscopic histopathological evaluation. The type of umbilical cord insertion and number of umbilical vessels were recorded. Velamentous cord insertion was defined as the insertion of umbilical cord into the amniotic membrane instead of the placental parenchyma. All twin placentas were injected according to the protocol published previously (Lopriore et al., 2011). After injection, the type and number of vascular anastomoses were documented. Digital placental pictures were taken for various further computerized analysis, such as measurement of placental share and anastomostic size. Individual placental share was measured as the venous return area of each twin using Image J 1.45s (Image J, National Institute of Health, USA). Placental share difference was calculated as the larger placental share minus the smaller placental share. Placental share discordance was calculated using the following formula: (larger placental share - smaller placental share)/larger placental share $\times 100 \%$. Part of the placental data were reported to describe a special type of AA and VV anastomoses, the so-called partially hidden AA and VV anastomoses (Zhao et al., 2015).

The following perinatal variables were collected prospectively: TTTS, TAPS, sIUGR, gestational age at birth, birth weight, $\mathrm{Hb}$ levels at birth, and delivery mode. Diagnosis of TTTS was based on the Eurofetus criteria (Senat et al., 2004). TAPS was defined as the diagnostic criteria proposed by Slaghekke et al. (2010). Birth weight discordance was calculated by the following formula: (larger twin - smaller twin)/larger twin $\times 100 \%$. sIUGR was defined as a birth weight discordance of $\geq 25 \%$ (Lopriore et al., 2012). Individual birth weight share was calculated by dividing the birth weight of each infant by the sum of the birth weights of both infants. Birth weight share/placental share ratio was calculated by dividing the birth weight share by the corresponding placental share (Lewi et al., 2007; Zhao et al., 2014).

\section{Statistics}

The Kolmogorov-Smirnov test was adopted to assess the normality of continuous variables. Data were analyzed using chi-square, Fisher exact, Mann-Whitney or Student $t$ tests, as appropriate. Spearman $r$ was generated to evaluate the correlation between placental share and birth weight share. Statistical significance was considered if a $p$ value was less than .05. Data were analyzed using GraphPad Prism v6.0 (GraphPad Software Inc. La Jolla, CA 92037 USA) and IBM SPSS Statistics $22.0^{\circledR}$ (IBM Corporation, Armonk, New York, USA).

\section{Results}

A cohort of 267 eligible twin placentas were examined at both centers during the study period, including $143 \mathrm{MC}$ placentas and 124 DC placentas. Nine (3\%) placentas were excluded due to incomplete injection. The remaining 134 MC placentas and 124 DC placentas were analyzed in this study. In the group of MC twins, 18 (13\%) were complicated with TTTS (not treated with fetoscopic laser surgery), and there were 8 cases $(6 \%)$ with TAPS and $31(23 \%)$ cases with growth discordance. Neither TTTS nor TAPS occurred in the group of DC twins, whereas growth discordance occurred in 10\% (12/124) of DC twins. Additional characteristics of the two groups are shown in Table 1.

Vascular anastomoses were detected in 99\% (133/134) MC placentas and $0 \%(0 / 124)$ DC placentas, respectively $(p<.01)$. In the group of MC placentas, the frequency of $\mathrm{AV}$ anastomoses, $\mathrm{AA}$ anastomoses, and $\mathrm{VV}$ anastomoses was, respectively, 99\% (133/134), 85\% (114/134), and 28\% (38/134). The median number of vascular anastomoses per MC placenta was 11 (interquartile 6-18). One percent (1/134) of MC placentas consisted of two separate placental masses (so-called bipartite MC placentas). Forty-four 
TABLE 2

Comparison of Placental Angio-Architecture Between MC and DC Placentas

\begin{tabular}{llll}
\hline & Monochorionic placentas $(n=134)$ & Dichorionic placentas $(n=124)$ & $p$ value \\
\hline Placentas with vascular anastomoses $-\mathrm{n}(\%)$ & $133(99)$ & 0 & $<.01$ \\
Velamentous cord insertion $-\mathrm{n}(\%)^{\mathrm{a}}$ & $58(22)$ & $28(11)$ & $10.8(6.2-19.0)$ \\
Placental share discordance $-\%$ & $19.8(8.1-33.3)$ & $29(23)$ & $<.01$ \\
Unequal placental share $\geq 20 \%-\mathrm{n}(\%)$ & $67(50)$ & $1.0(0.91-1.11)$ & $<.01$ \\
birth weight share/placental share ratio & $1.0(.87-1.20)$ & .33 \\
\hline
\end{tabular}

Note: Data were displayed as median (IQR) or $\mathrm{n}(\%)$. ${ }^{\mathrm{a}}$ Denotes the presence of velamentous cord insertion per infant instead of twin pair. b Value was given as median $(95 \% \mathrm{Cl})$.

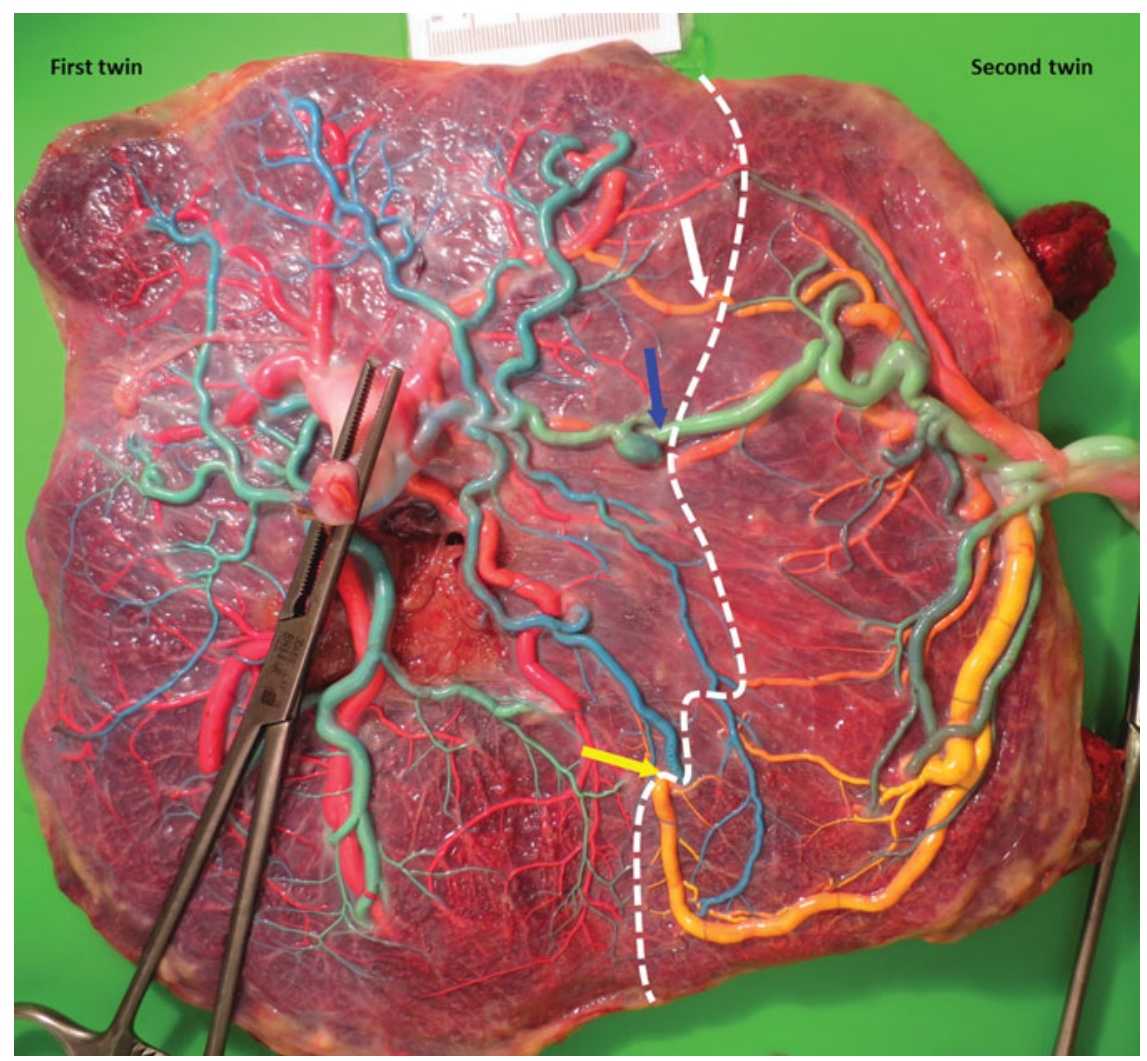

\section{FIGURE 1}

(Colour online) A monochorionic placenta after colored dye injection. The blue, white and yellow arrows indicate the AA anastomoses, VV anastomosis and AV anastomoses, respectively. The white-dotted line indicates the vascular equator. The first twin had a placental share of $67 \%$ and the second twin $33 \%$.

percent (54/124) of DC placentas had two separate placental masses, whereas the rest of DC placentas were fused. Comparisons of placental characteristics between $\mathrm{MC}$ and DC placentas are summarized in Table 2. Examples of MC and DC placentas after colored dye injection are illustrated in Figures 1 and 2, respectively.

We further related the individual placental share to birth weight share in MC and DC twins to evaluate the relation between fetal growth and placenta share. We found that birth weight was significantly associated with placental share in both MC twins (Spearman $r=0.64,95 \%$ confidence interval 0.56-0.71, $p<.01$, Figure 3 ) and DC twins
(Spearman $r=0.32,95 \%$ confidence interval 0.19-0.44, $p<.01$, Figure 3 ).

\section{Discussion}

This is the first study to compare the angioarchitecture between MC and DC placentas using an accurate and reliable technique. We found that vascular anastomoses are almost always present in MC placentas but non-existent in DC placentas. As a result, hematological and perinatal complications due to shared circulation by vascular anastomoses occur only in MC twins, but not in DC twins. 


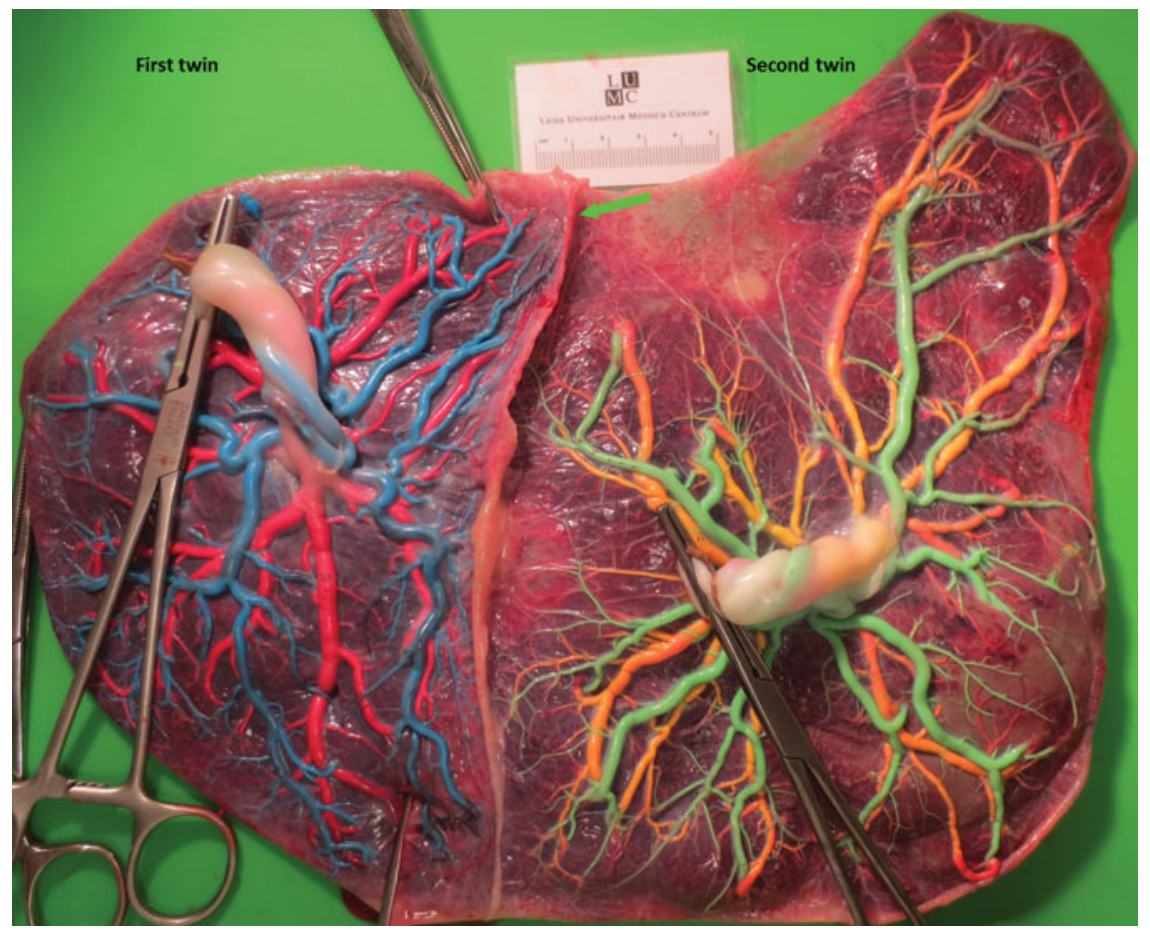

\section{FIGURE 2}

(Colour online) A dichorionic placenta after colored dye injection. The two placental masses were fused. No vascular anastomoses were detected after injection. The green arrow indicates the inter-twin septum. The individual placental share in first and second twin was $39 \%$ and $61 \%$.

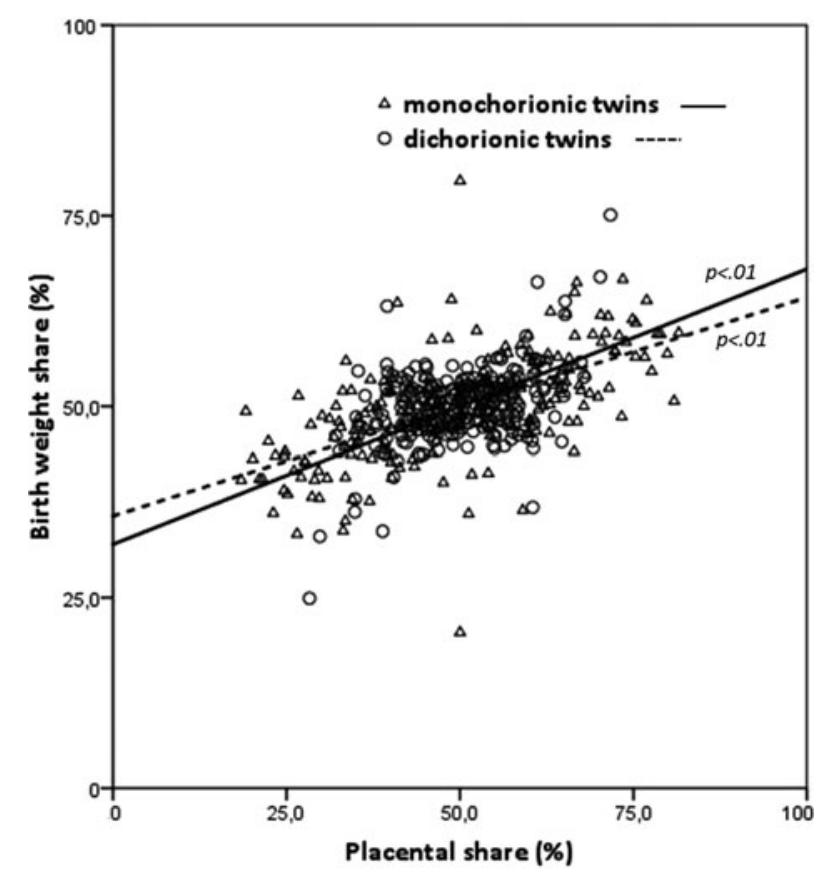

FIGURE 3

Correlation between placental share and birth weight in MC twins (Spearman $r=0.64 ; 95 \% \mathrm{Cl}: 0.56-0.71 ; p<.01$ ) and DC twins (Spearman $r=0.32 ; 95 \% \mathrm{Cl}: 0.19-0.44 ; p<.01)$.
The vascular anastomoses and associated consequences in MC twins have been well studied. In accordance with previous placental injection studies, this study shows that the presence of vascular anastomoses in MC placentas is quite common (De Paepe et al., 2002; Lewi et al., 2007; Robertson \& Neer, 1983; Zhao et al., 2013). In contrast, the presence of vascular anastomoses in DC placentas has not systematically been studied with colored dye injection. However, several case reports have reported on DC twins with placental vascular anastomoses (Biran et al., 2011; French et al., 1998; Lage, 1989; Phelan et al., 1998; Quintero et al., 2010; Rodriguez et al., 1996). In these reports, vascular anastomoses were inspected when associated complications were suspected, such as TTTS, TAPS, and twin reversed arterial perfusion (TRAP). Nevertheless, Robertson and Neer (1983) reported a paucity of vascular anastomoses in DC placentas with a fused mass. Thus, the vascular anastomoses in the general population of DC twins remains uncertain. In this study, we consecutively examined a large cohort of DC placentas with colored dye injection and did not detect any vascular anastomoses. This disparity in vascular anastomoses between MC and DC placentas may be due to the distinct embryological process. In DC twins, a prerequisite for the formation of vascular anastomoses is that the chorionic vessels of one twin pass through the chorion and amnion of both twins into the placental territory of the co-twin. This process may be not only hampered by 
mechanical factors, but also be inhibited by the chemical factors in amnion (Niknejad et al., 2013).

In this study, we found that birth weight was strongly associated with placental share in both MC and DC twins. Our findings support the theory proposed by Salafia et al. (2016) that the growth relationship between birth weight and placental weight is comparable between MC twins and DC twins. Interestingly, unequal placental share appears to be less frequent in DC twins than MC twins despite the common existence of inter-twin competition for space and nutrition in both types of twins. Several studies argue that the blastocyst allocated to each twin is disequilibrated during the twining process of MC twins, leading to different growth potential within twin pairs (Silva et al., 2011). In addition, implantation into an unfavorable milieu of one twin may also play a role in the increased frequency of unequal placental share in MC twins, given the higher prevalence of velamentous cord insertion indicative of insufficient placentation (Costa-Castro et al., 2013).

This study has several limitations. One is the selection bias due to the referral nature of our centers. Twin pregnancies referred to our centers usually undergo a complicated course, especially MC twins. Since vascular anastomoses and unequal placental share are significantly related to the adverse outcome in MC twins (Lewi et al., 2013), the findings on MC twins in this study may be overestimated. However, the prevalence of TTTS, TAPS, and sIUGR detected in the MC twin cohort in this study is comparable to the expected prevalence in an unselected cohort of MC twins (Lewi et al., 2008). Another possible limitation is that individual placental share in DC twins may not represent the size of individual placental mass. Placentometric studies show that many aspects of placental gross morphology are associated with fetal growth, including area of placental surface and placental weight (Barker \& Thornburg, 2013). Unfortunately, the weight of individual placental mass was not measured in this study. Finally, minuscule vascular anastomoses have also been discovered underneath the placental surface using a casting technique with latex injection. In this study, placental casting was not performed and the presence of deep-hidden anastomoses was not evaluated (van den Wijngaard et al., 2007).

In conclusion, vascular anastomoses are extremely rare (and almost non-existent) in DC placentas, but ubiquitous in MC placentas. In addition, unequal placental sharing appears to occur more frequently in MC twin placentas. The two placental characteristics are responsible for the increased risk of perinatal complications associated with MC twinning.

\section{References}

Barker, D. J., \& Thornburg, K. L. (2013). Placental programming of chronic diseases, cancer and lifespan: A review. Placenta, 34, 841-845.
Biran, V., Bornes, M., Aboura, A., Masmoudi, S., Drunat, S., Baumann, C., ... Baud, O. (2011). A long-term competent chimeric immune system in a dizygotic dichorionic twin. Pediatrics, 128, e458-463.

Costa-Castro, T., De Villiers, S., Montenegro, N., Severo, M., Oepkes, D., Matias, A., \& Lopriore, E. (2013). Velamentous cord insertion in monochorionic twins with or without twin-twin transfusion syndrome: Does it matter? Placenta, 34, 1053-1058.

De Paepe, M. E., Burke, S., Luks, F. I., Pinar, H., \& Singer, D. B. (2002). Demonstration of placental vascular anatomy in monochorionic twin gestations. Pediatric and Developmental Pathology, 5, 37-44.

De Paepe, M. E., Shapiro, S., Greco, D., Luks, V. L., Abellar, R. G., Luks, C. H., \& Luks, F. I. (2010). Placental markers of twin-to-twin transfusion syndrome in diamnioticmonochorionic twins: A morphometric analysis of deep artery-to-vein anastomoses. Placenta, 31, 269-276.

de Villiers, S. F., Slaghekke, F., Middeldorp, J. M., Walther, F. J., Oepkes, D., \& Lopriore, E. (2013). Placental characteristics in monochorionic twins with spontaneous versus post-laser twin anemia-polycythemia sequence. Placenta, 34, 456-459.

de Villiers, S. F., Zhao, D. P., Cohen, D., van Zwet, E. W., Duan, T., Oepkes, D., \& Lopriore, E. (2015). Correlation between veno-venous anastomoses, TTTS and perinatal mortality in monochorionic twin pregnancies. Placenta, 36, 603-606.

Denbow, M. L., Cox, P., Taylor, M., Hammal, D. M., \& Fisk, N. M. (2000). Placental angioarchitecture in monochorionic twin pregnancies: Relationship to fetal growth, fetofetal transfusion syndrome, and pregnancy outcome. American Journal of Obstetrics and Gynecology, 182, 417-426.

Fick, A. L., Feldstein, V. A., Norton, M. E., Wassel Fyr, C., Caughey, A. B., \& Machin, G. A. (2006). Unequal placental sharing and birth weight discordance in monochorionic diamniotic twins. American Journal of Obstetrics and Gynecology, 195, 178-183.

French, C. A., Bieber, F. R., Bing, D. H., \& Genest, D. R. (1998). Twins, placentas, and genetics: Acardiac twinning in a dichorionic, diamniotic, monozygotic twin gestation. Human Pathology, 29, 1028-1031.

Lage, J. M., Vanmarter, L. J., \& Mikhail, E. (1989). Vascular anastomoses in fused, dichorionic twin placentas resulting in twin transfusion syndrome. Placenta, 10, 55-59.

Lewi, L., Cannie, M., Blickstein, I., Jani, J., Huber, A., Hecher, K., ... Deprest, J. (2007). Placental sharing, birthweight

discordance, and vascular anastomoses in monochorionic diamniotic twin placentas. American Journal of Obstetrics and Gynecology, 197, 587, e581-588.

Lewi, L., Deprest, J., \& Hecher, K. (2013). The vascular anastomoses in monochorionic twin pregnancies and their clinical consequences. American Journal of Obstetrics and Gynecology, 208, 19-30.

Lewi, L., Jani, J., Blickstein, I., Huber, A., Gucciardo, L., Van Mieghem, T., ... Deprest, J. (2008). The outcome of monochorionic diamniotic twin gestations in the era of invasive fetal therapy: A prospective cohort study. American Journal of Obstetrics and Gynecology, 199, (5), 514.e1-8. 
Lopriore, E., Pasman, S. A., Klumper, F. J., Middeldorp, J. M., Walther, F. J., \& Oepkes, D. (2012). Placental characteristics in growth-discordant monochorionic twins: A matched case-control study. Placenta, 33, 171-174.

Lopriore, E., Slaghekke, F., Middeldorp, J. M., Klumper, F. J., van Lith, J. M., Walther, F. J., \& Oepkes, D. (2011). Accurate and simple evaluation of vascular anastomoses in monochorionic placenta using colored dye. Journal of Visualized Experiments, 5, (55), e3208.

Lopriore, E., van den Wijngaard, J. P., Middeldorp, J. M., Oepkes, D., Walther, F. J., van Gemert, M. J., \& Vandenbussche, F. P. (2007). Assessment of feto-fetal transfusion flow through placental arterio-venous anastomoses in a unique case of twin-to-twin transfusion syndrome. Placenta, 28, 209-211.

Niknejad, H., Paeini-Vayghan, G., Tehrani, F. A., KhayatKhoei, M., \& Peirovi, H. (2013). Side dependent effects of the human amnion on angiogenesis. Placenta, 34, 340-345.

Phelan, M. C., Geer, J. S., \& Blackburn, W. R. (1998). Vascular anastomoses leading to amelia and cutis aplasia in a dizygotic twin pregnancy. Clinical Genetics, 53, 126-130.

Quintero, R., Kontopoulos, E. V., Barness, E., Steffensen, T. S., Hilbelink, D., Chmait, R., ... Bornick, P. W. (2010). Twintwin transfusion syndrome in a dichorionic-monozygotic twin pregnancy: The end of a paradigm?. Fetal and Pediatric Pathology, 29, 81-88.

Robertson, E. G., \& Neer, K. J. (1983). Placental injection studies in twin gestation. American Journal of Obstetrics and Gynecology, 147, 170-174.

Rodriguez, J. G., Porter, H., Stirrat, G. M., \& Soothill, P. W. (1996). Twin to twin blood transfusion in a dichorionic pregnancy without the oligohydramnios-polyhydramnios sequence. British Journal of Obstetrics and Gynaecology, 103, 1056.

Salafia, C. M., Kiryankova, N., Inany, H., Charlagorla, P., Park, M., Khawar, N., ... Lederman, S. (2016). Metabolic scaling and twin placentas. Placenta, 37, 16-18.
Sebire, N. J., Snijders, R. J., Hughes, K., Sepulveda, W., \& Nicolaides, K. H. (1997). The hidden mortality of monochorionic twin pregnancies. British Journal of Obstetrics and Gynaecology, 104, 1203-1207.

Senat, M. V., Deprest, J., Boulvain, M., Paupe, A., Winer, N., \& Ville, Y. (2004) Endoscopic laser surgery versus serial amnioreduction for severe twin-to-twin transfusion syndrome. New England Journal of Medicine, 351, 136-144.

Silva, S., Martins, Y., Matias, A., \& Blickstein, I. (2011). Why are monozygotic twins different?. Journal of Perinatal Medicine, 39, 195-202.

Slaghekke, F., Kist, W. J., Oepkes, D., Pasman, S. A., Middeldorp, J. M., Klumper, F. J., ... Lopriore, E. (2010) Twin anemia-polycythemia sequence: Diagnostic criteria, classification, perinatal management and outcome. Fetal Diagnosis and Therapy, 27, 181-190.

van den Wijngaard, J. P., Lopriore, E., van der Salm, S. M., Schaap, A. H., Vandenbussche, F. P., Deruiter, M. C., \& van Gemert, M. J. (2007). Deep-hidden anastomoses in monochorionic twin placentae are harmless. Prenatal Diagnosis, 27, 233-239.

Zhao, D. P., Cohen, D., Middeldorp, J. M., Klumper, F. J., Haak, M. C., Oepkes, D., \& Lopriore, E. (2014). The role of venovenous anastomoses in twin-twin transfusion syndrome. Placenta, 35, 334-336.

Zhao, D. P., Dang, Q., Haak, M. C., Middeldorp, J. M., Klumper, F. J., Oepkes, D., \& Lopriore, E. (2015). 'Superficial' anastomoses in monochorionic placentas are not always superficial. Placenta, 36, 1059-1061.

Zhao, D. P., de Villiers, S. F., Slaghekke, F., Walther, F. J., Middeldorp, J. M., Oepkes, D., \& Lopriore, E. (2013). Prevalence, size, number and localization of vascular anastomoses in monochorionic placentas. Placenta, 34, 589-593.

Zhao, D., Slaghekke, F., Middeldorp, J. M., Duan, T., Oepkes, D., \& Lopriore, E. (2014). Placental share and hemoglobin level in relation to birth weight in twin anemiapolycythemia sequence. Placenta, 35, 1070-1074. 